\title{
Dynamic Response of Aluminum Honeycomb Sandwich Plate Subjected to Impact by Flying Spear
}

\author{
Chun Cheng, Xi Chen, Zhonghua Du, Zhaojun Pang and Jiyue Si \\ School of Mechanical Engineering, Nanjing University of Science and Technology, 210094Nanjing , China
}

\begin{abstract}
Numerical simulation and experiment were applied to study the dynamic response of aluminum honeycomb sandwich plate subjected to the impact by flying spear as well as the the proper velocity of the flying spear impacting on the plate. The deformation mode and damage form of the aluminum honeycomb sandwich plate were obtained. Moreover, the proper velocity of the flying spear is around $40 \mathrm{~m} / \mathrm{s} \sim 50 \mathrm{~m} / \mathrm{s}$. It is confirmed that The deformation area of the upper and lower panels decreases with the increase of the impact velocity, whereas the buckling angle of the panel increases with the increase of the impact velocity. The damage forms of the aluminum honeycomb cell are collapse and buckling sequentially from the impact point to the surrounding. In addition, The collapse area of the honeycomb cells increases with the increase of the maximum diameter of the flying spear and the range of buckling decreases with the increase of impact velocity. The experimental results are in good agreement with the simulation results.
\end{abstract}

\section{INTRODUCTION}

The aluminum honeycomb sandwich plate is widely used in aviation, aerospace, shipbuilding, automobile, wind energy system, rail locomotives and other industrial fields due to its excellent energy absorption function, high specific strength and low density[1-3]. Based on its wide application in various industries, the dynamic response of aluminum honeycomb sandwich plate under different load conditions has been a hot topic in recent years. P Ren[4] considered the dynamic response and impact resistance of aluminum alloy honeycomb sandwich plate subjected to the underwater explosion shock wave loading using the underwater explosion shock wave loading device. He found that when compared with mono-layer plate with the same surface density, the compress of aluminum honeycomb core subjected to underwater shock loading can effectively reduce the plastic deformation of the back panel and improve the overall impact resistance of sandwich structures. Y Song[5]found the deflection of the back plate of the clamped square after impacted by foam metal bullet reaches the maximum at the center and minimizes around the edge, the overall deformation of the sandwich panels is quaquaversal. J Hang[6] carried out hyper-velocity impact test and numerical simulation for honeycomb sandwich structure with insulation layer. The results showed that honeycomb core restricts radial expansion of debris cloud. M Hozhar[7] analyzed the dynamic response of aluminum honeycomb sandwich plate with different foam filling materials under different impact loads using finite element method, and carried out the crash-worthiness design of the structure. The dynamic response and deformation of aluminum honeycomb sandwich plates with different thickness under the explosive load were studied by $\mathrm{S} \mathrm{Li}$, and the numerical simulation was carried out with LS-DYNA[8]. $\mathrm{H}$ Zhou[9] studied the dynamic response and energy absorption of the honeycomb sandwich structures with the same mass and thickness but different densities under high speed impact.

The good energy absorption function of aluminum honeycomb sandwich plate was conformed by the above studies, therefore the aluminum honeycomb sandwich plate is widely used in aviation and spaceflight[1]. The Earth orbit is in a serious predicament caused by millions of space debris. Operational satellite vital for mankind infrastructure are threatened to be destroyed by space debris. These space debris produced by invalid satellites or a rocket fragments. Many enabling space debris capturing and removal methods have been proposed in the past decade and several methods have been tested on ground and/or in parabolic flight experiments[10-12]. The sketch map of a capture system suing flying spears is shown in Figure 1, which is designed to capture and remove the invalid satellites and space debris or remove from orbit. Based on the flying spear capture system, in this paper we studied the dynamic response of aluminum honeycomb sandwich plate which is applied to satellite under the impact of flying spear. Through experiment and numerical simulation, The deformation mode and damage form of aluminum honeycomb sandwich plate and the impact velocity of the correct action of flying spear were obtained, which providing theoretical and experimental basis for further improvement of the flying spear capture system. 


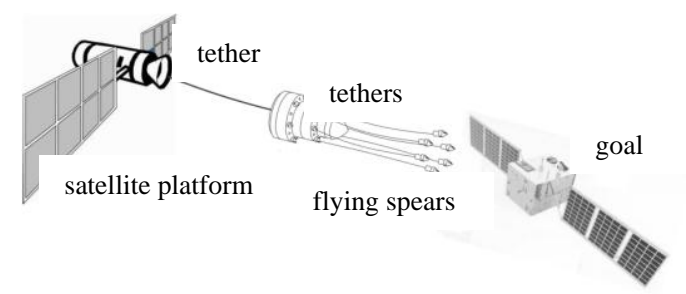

Figure1. Design scheme of a capture system using flying spears

\section{Numerical simulation}

\subsection{Numerical simulation model}

The numerical simulation of a flying spear impacting on aluminum honeycomb sandwich plate was carried out by the LS-DYNA. The thickness of the upper and lower panels on the aluminum honeycomb sandwich plate is $1 \mathrm{~mm}$. The section of a single honeycomb cell is regular hexagon, the thickness and length of the cell wall are $0.1 \mathrm{~mm}$ and $8 \mathrm{~mm}$ respectively, and the height of the cell is $8 \mathrm{~mm}$. In order to avoid the termination of the calculation, the grids of the head of the spear and the center of the aluminum honeycomb sandwich plate were refined by the hexahedron mesh. Johnson-Cook material model and Gruneisen equation of state were used for both flying spear and aluminum honeycomb sandwich plate. $45 \#$ steel was chose for the spear. There is no plastic deformation and failure of the flying spear in the process of impact. Therefore, the Johnson-Cook constitutive relation of 45\# steel was only considered in numerical calculation, and the failure of material was not considered. The main parameters of $45 \#$ steel are shown in Table1[13]. 2A12 aluminum was used for aluminum honeycomb sandwich plate and honeycomb cells. The plastic deformation and damage of the sandwich plate under the impact condition are large, so the modified Johnson-Cook model was used for it.
The expression of the Johnson-Cook strength model is as follows,

$$
\sigma_{e q}=\left(A+B \varepsilon^{n}\right)\left(1+C \ln \frac{\dot{\varepsilon}}{\dot{\varepsilon}_{0}}\right)\left(1-T^{* m}\right)
$$

Where $\sigma_{e q}$ denotes equivalent stress, $\mathrm{A}$ is the yield strength of material at reference strain rate and reference temperature, the coefficients $\mathrm{B}, \mathrm{C}$ and $\mathrm{m}$ denote strain-strengthening coefficient, the coefficient of strain-rate sensitivity and coefficient of softing due to temperature respectively, the exponent $\mathrm{n}$ denotes strain-strengthening exponent, $\dot{\varepsilon}_{0}$ is user - defined reference strain rate which is usually set to 1 .

$$
T^{*}=\left(T-T_{\text {room }}\right) /\left(T_{\text {melt }}-T_{\text {room }}\right)
$$

Where $T, T_{\text {room }}$ and $\boldsymbol{T}_{\text {melt }}$ are absolute temperature, room temperature and melting temperature of the material respectively.

The failure of 2A12 aluminum can be calculated by Johnson-Cook failure model,

$$
\varepsilon_{f}=\left[D_{1}+D_{2} \exp \left(D_{3} \sigma^{*}\right)\right] \cdot\left[1+D_{4} \ln \frac{\dot{\varepsilon}}{\dot{\varepsilon}_{0}}\right] \cdot\left[1+D_{5} T^{*}\right]
$$

Where $\sigma^{*}$ is stress triaxiality, $D_{1} \sim D_{5}$ all are material parameters. The modified Johnson-Cook failure model was obtained by modifying the temperature softening term into an exponential form because the fracture strain obtained by tensile test at different temperatures does not have a linear relationship with the temperature[14],

$$
\varepsilon_{f}=\left[D_{1}+D_{2} \exp \left(D_{3} \sigma^{*}\right)\right] \cdot\left[1+D_{4} \ln \frac{\dot{\varepsilon}}{\dot{\varepsilon}_{0}}\right] \cdot\left[1+D_{5}\left(1-\exp \left(D_{6} T^{*}\right)\right)\right]
$$

Where $D_{1} \sim D_{6}$ all are material parameters. The values of each parameter in the Johnson-Cook strength model and the failure model are shown in Table 2. The contact between the flying spear and the aluminum honeycomb sandwich plate adopted the erosion contact algorithm. The cell model of aluminum honeycomb sandwich plate and 1/4 calculation model are shown in Figure 2 and Figure 3 respectively.

Table.1 Main material parameters of $45 \#$ steel

\begin{tabular}{|c|c|c|c|c|c|c|c|c|}
\hline Density $/ \mathrm{g} \cdot \mathrm{cm}^{-3}$ & Poisson's ratio & Young's modulus/GPa & $A / \mathrm{MPa}$ & $B / \mathrm{MPa}$ & $n$ & $C_{l}$ & $C_{2}$ & $m$ \\
\hline 7.83 & 0.3 & 210 & 497.75 & 647.15 & 0.393 & $2.76 \times 10^{-3}$ & 0.4 & 0.626 \\
\hline
\end{tabular}

Table.2 Johnson-Cook strength model parameters of 2A12 aluminum

\begin{tabular}{|c|c|c|c|c|c|c|c|c|c|c|}
\hline $\begin{array}{c}\text { Young's } \\
\text { modulus/GPa }\end{array}$ & Poisson's ratio & $\begin{array}{c}\text { Density } \\
/ \mathrm{g} \cdot \mathrm{cm}^{-3}\end{array}$ & $\beta^{\mathrm{a}}$ & $T_{\text {room }} / \mathrm{K}$ & $T_{\text {melt }} / \mathrm{K}$ & $m$ & $c_{l}$ & $c_{2}{ }{ }$ & $\sigma_{n}{ }^{\mathrm{b}} / \mathrm{MPa}$ & $\varepsilon_{n}{ }^{\mathrm{c}}$ \\
\hline 71.7 & 0.33 & 2770 & 0.9 & 293 & 863 & 1.426 & 0.071 & 288 & 635 & 0.126 \\
\hline $\begin{array}{c}\text { Yield } \\
\text { strength/MPa }\end{array}$ & $\begin{array}{c}\text { Specific heat } \\
/ \mathrm{J} \cdot(\mathrm{kgK})^{-1}\end{array}$ & strain rate & $\omega$ & $C$ & $D_{1}$ & $D_{2}$ & $D_{3}$ & $D_{4}$ & $D_{5}$ & $D_{6}$ \\
\hline 400 & 921 & 0.00111 & 0 & 0.001 & 0.116 & 0.211 & -2.172 & 0.012 & 0.0126 & 13.04 \\
\hline
\end{tabular}

\footnotetext{
${ }^{\mathrm{b}} \sigma_{n}$-Necking stress

${ }^{c} \varepsilon_{n}$-Necking strain
}

${ }^{a} \beta$ - Conversion coefficient of plastic work 

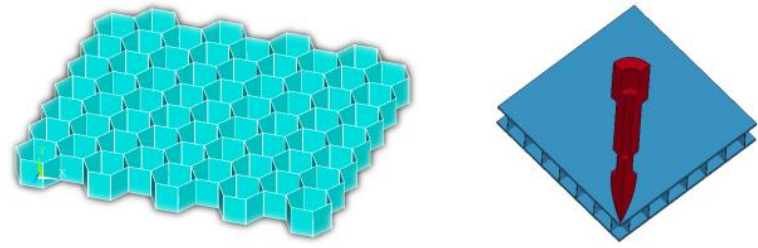

Figure 2. Cell model

Figure 3. 1/4 calculation model

\subsection{Numerical simulation results and analysis}

The dynamic response of aluminum honeycomb sandwich plate under different impulse was studied.The impact velocity was set at $50 \mathrm{~m} / \mathrm{s}, 60 \mathrm{~m} / \mathrm{s}, 70 \mathrm{~m} / \mathrm{s}, 80 \mathrm{~m} / \mathrm{s}$ and $90 \mathrm{~m} / \mathrm{s}$ respectively. The $1 / 2$ frame diagram and $1 / 2$ open view of the damage of the sandwich plate were shown in Figure 4 as the spear impacted on the aluminum honeycomb sandwich plate at different velocities.

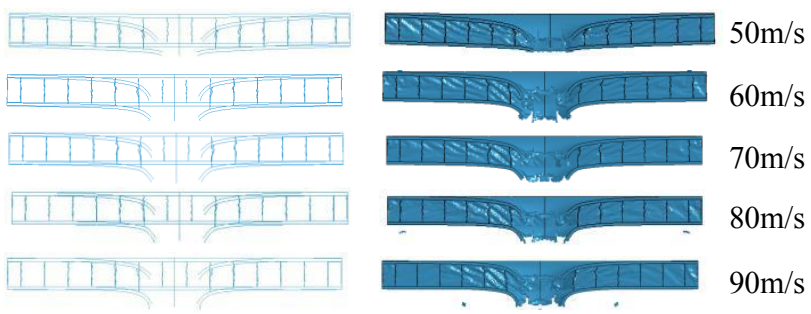

Figure 4 1/2 frame diagram and 1/2 open view of the plates

From Figure 4, it can be seen that the main damage forms of the upper and lower panels of the sandwich plate are shear tear and buckling deformation. When the impact velocity is lower, the buckling deformation area of the upper and lower panels is larger, and the flexion angle of the panel is smaller. Whereas, when the impact velocity is higher, the diameter of the buckling deformation area of the upper and lower panels is smaller, and the flexion angle of the panel is larger. However, the buckling angle of the upper panel is always less than the buckling angle of the lower panel, which is related to the aluminum honeycomb cell. The aluminum honeycomb cell hindered shear tear and buckling deformation of the upper panel. The failure form of aluminum honeycomb cell appears to be collapse and buckling successively from the impact center outwards. The collapse area of the aluminum honeycomb cells is relevant to the maximum diameter of the flying spear, but it has nothing to do with the impact velocity. Whereas, the bucking area decreases with the increase of impact velocity.

The velocity of the correct action of the spear refers to the velocity of the flying spear to capture the satellite correctly, which means the main flying spear embeds in the sandwich plate and the barbs on the flying spear open after the flying spear penetrates the aluminum honeycomb sandwich plate on the satellite. We define this velocity as the proper velocity of the flying spear which is an important parameter for the the flying spear capture system.

It can be seen from the results of numerical simulation that when the velocity of the flying spear was $40 \mathrm{~m} / \mathrm{s}$, the spear penetrated the aluminum honeycomb sandwich plate only with the tip of the head, and the rest failed to penetrate the plate as seen in Figure 5 (on the left ). Whereas when the impact velocity was $50 \mathrm{~m} / \mathrm{s}$, the most part of the flying spear penetrated the aluminum honeycomb sandwich plate but the thicker part on the back embedded in it as shown in Figure 5 (on the right ) and the velocity curve of the flying spear in the process of penetrating the aluminum honeycomb sandwich plate is shown in Figure 6. It can be seen from Figure 6, the velocity of the spear was slowly reduced to about $32 \mathrm{~m} / \mathrm{s}$, and it penetrated into the aluminum honeycomb sandwich plate at a speed of $32 \mathrm{~m} / \mathrm{s}$ for a period of time, then it sharply reduced to zero, and then increased to $5 \mathrm{~m} / \mathrm{s}$ in reverse direction. The reason for the reverse acceleration of the flying spear is that when the velocity of the spear was reduced to zero, a slight rebound occurred on the aluminum honeycomb sandwich plate. It is can be conjectured from the results of numerical simulation that when the impacting velocity is between $40 \mathrm{~m} / \mathrm{s}$ and $50 \mathrm{~m} / \mathrm{s}$, the flying spear will penetrate the aluminum honeycomb sandwich plate and embed therein, and the barbs on the spear open. In other words the proper velocity of the flying spear is around $40 \mathrm{~m} / \mathrm{s} \sim 50 \mathrm{~m} / \mathrm{s}$.

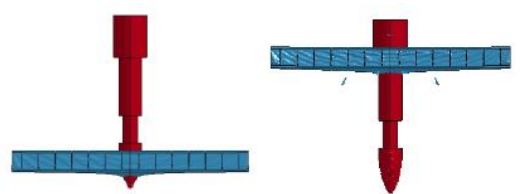

Figure 5. Simulation results under the impact velocities of $40 \mathrm{~m} / \mathrm{s}$ and $50 \mathrm{~m} / \mathrm{s}$

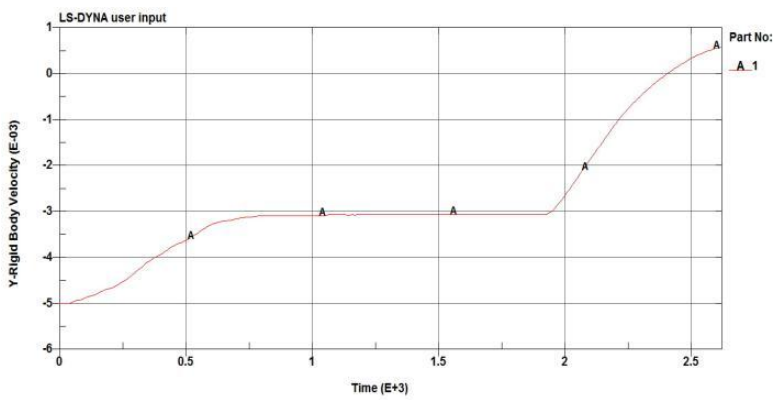

Figure 6. Velocity of flying spear during the perforation under the impact velocity of $50 \mathrm{~m} / \mathrm{s}$

\section{Experiment and experimental results}

\subsection{Experimental condition}

The physical picture of the flying spear with its launcher are shown in Figure 7. The launcher mainly consist of a shell, an end cap, a storage tube for tether, a seal cover and some tether. The end cap was in fixed connection with the shell by screw and the cavity formed between the end cap and the shell was used to install the propellant. Thread connection was used between the storage tube for tether and the end cap. One end of the tether was tied with the spear. A conical slot was machined in the shell which was used to plant a nylon conical device. The nylon conical device connected with the end of the spear by thread was used to seal up gunpowder gas and push the spear forwards. The head of the spear and the cylindrical part of the spear were 
threaded through a thread, and the barbs were set between the head of the spear and the cylindrical part of the spear.

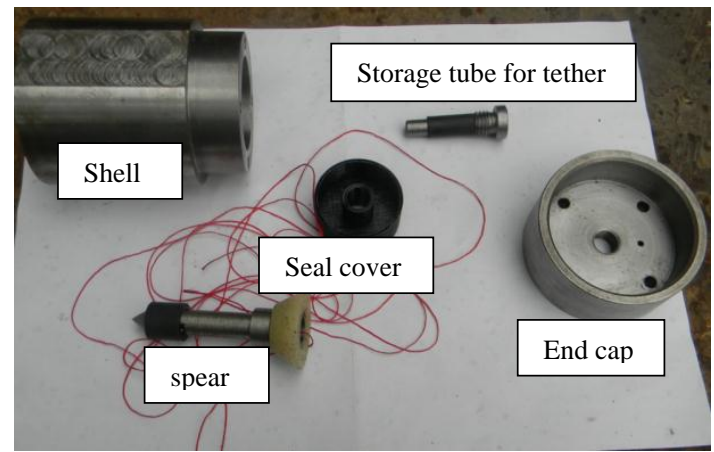

Figure 7. Physical picture of the flying spear and its launcher

The experimental layout is shown in Figure 8. A bench vice was used to fix the launching device. The aluminum honeycomb sandwich plate was fixed at one end of the target frame. Two pieces of aluminum foil paper for speed measurement was used in one experiment, one placed before the aluminum honeycomb sandwich plate and the other one set on one end of the target frame near the bench vice. The other end of the wire used to measure velocity placed at insecurity area. The propellant was ignited by electrical trigger primer.The thickness of the upper and lower panels made by $2 \mathrm{~A} 12$ aluminum on the aluminum honeycomb sandwich plate is $1 \mathrm{~mm}$. The section of the a single honeycomb cell is regular hexagon, the thickness and length of the cell wall are $0.1 \mathrm{~mm}$ and $8 \mathrm{~mm}$ respectively, and the height of the cell is $8 \mathrm{~mm}$. The overall size of an aluminum honeycomb sandwich plate is $200 \mathrm{~mm} \times 200 \mathrm{~mm} \times 10 \mathrm{~mm}$. In the experiment, the impact velocity of the spear was controlled by adjusting the charge amount of the propellant.

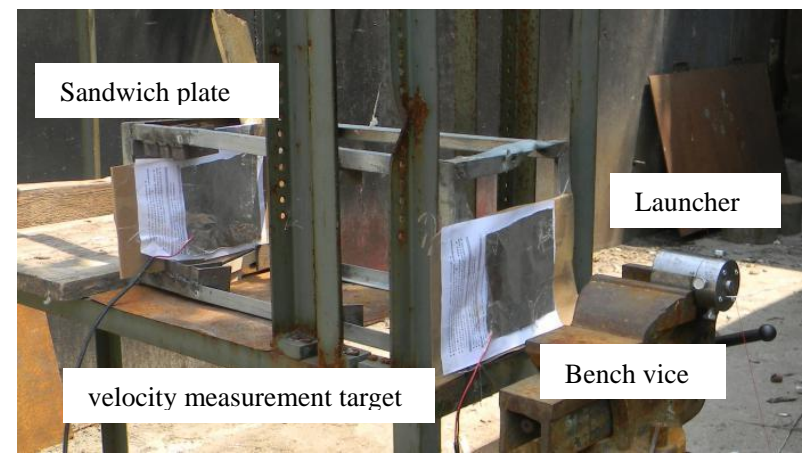

Figure 8. Experimental setup

\subsection{Experimental results and analysis}

There were 5 spears were launched in the experiment, of which two flying spears failed to impact the aluminum honeycomb sandwich plate correctly due to the poor working accuracy of the spear. The velocities of the other three spears impacting the aluminum honeycomb sandwich panels vertically were $47 \mathrm{~m} / \mathrm{s}$, $60 \mathrm{~m} / \mathrm{s}, 92 \mathrm{~m} / \mathrm{s}$ respectively. When the impact velocity were $60 \mathrm{~m} / \mathrm{s}$ and $92 \mathrm{~m} / \mathrm{s}$, the spears penetrated the aluminum honeycomb sandwich plates. The perforation and open view of aluminum honeycomb sandwich plates are shown in Figure 9 and Figure 10.
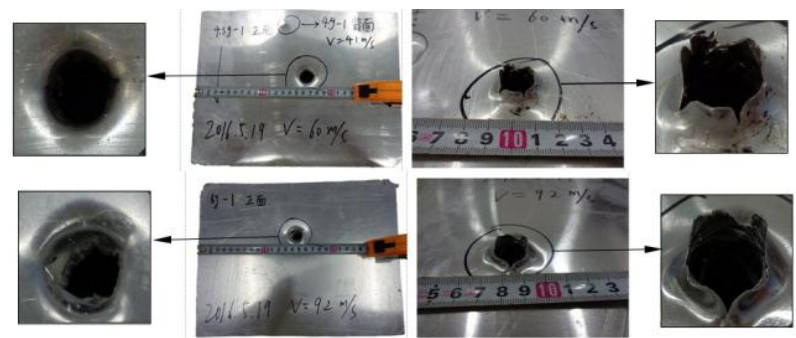

Figure 9. Experimental results under the impact velocities of $60 \mathrm{~m} / \mathrm{s}$ and $92 \mathrm{~m} / \mathrm{s}$

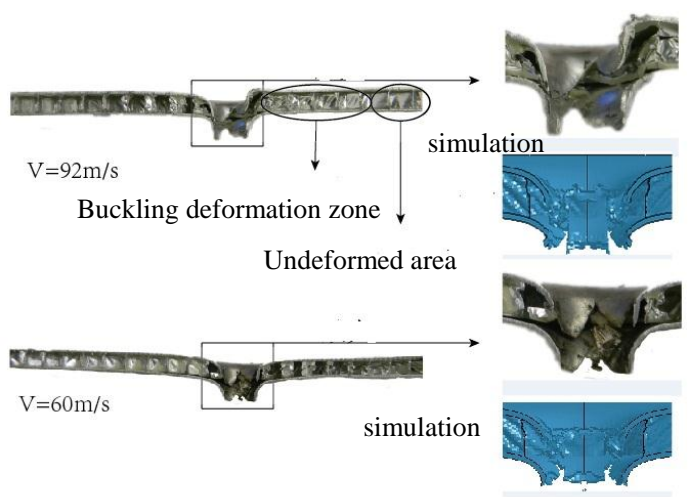

Figure 10. Open view of aluminum honeycomb sandwich plates

It can be seen from Figure 9, there were perforations formed by shear tear at the impact point on the upper panels of the aluminum honeycomb sandwich plates (the panels near the launcher and on the left in the figure), the plastic deformation occurred around the perforation, and the panels flexed inside the sandwich plates. Petal shaped perforations were produced on the lower panels of the aluminum honeycomb sandwich plates (on the right in the figure), When the impact velocity is $60 \mathrm{~m} / \mathrm{s}$, the diameter of buckling plastic deformation zone on the upper panel is $34 \mathrm{~mm}$ and that on the lower panel is $26 \mathrm{~mm}$; whereas when the impact velocity is $90 \mathrm{~m} / \mathrm{s}$, the diameter of buckling plastic deformation zone on the upper panel is $32 \mathrm{~mm}$, that on the lower panel is $24 \mathrm{~mm}$; buckling deformation area on the upper and lower panel shows a decreasing trend as the impact velocity increases. It can be clearly seen from Figure 10, the honeycomb cells collapsed in and around the perforations, buckled near the perforations and did not deform obviously at areas far from the perforations. the range of buckling decreases with the increase of impact velocity. It can be seen from the perforation magnification view that the buckling angle of the upper and lower panels increases with the increase of the impact velocity. The damage and deformation of the upper and lower panels and the honeycomb cells obtained in the experiment are in agreement with the simulation results.

In the experiment, the flying spear with the impact velocity of $47 \mathrm{~m} / \mathrm{s}$ penetrated the aluminum honeycomb sandwich plate and embedded in it as seen in Figure 11. It is proved that the conjecture from the numerical simulation is correct. That is the proper velocity of the flying spear is around $40 \mathrm{~m} / \mathrm{s} \sim 50 \mathrm{~m} / \mathrm{s}$. 


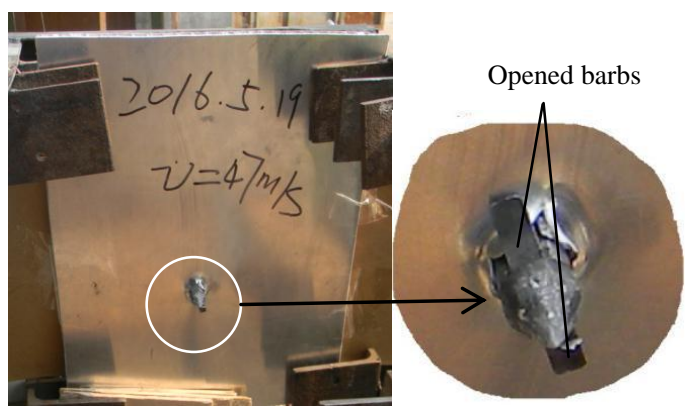

Figure 11. Experimental results under the impact velocity of $47 \mathrm{~m} / \mathrm{s}$

\section{Conclusions}

The dynamic response of the aluminum honeycomb sandwich plate under the impact of flying spear was studied by numerical simulation and experiment, and the following conclusions were obtained.

a.The main damage and failure modes of the upper and lower panels of the sandwich plate are shear tear and buckling deformation. The buckling deformation area of the upper and lower panels decreases with the increase of the impact velocity, whereas the buckling angle of the panel increases with the increase of the impact velocity.

b. The damage forms of the aluminum honeycomb cell are collapse and buckling sequentially from the impact center to the surrounding. The collapse area of the honeycomb cells increases with the increase of the maximum diameter of the flying spear and the range of buckling decreases with the increase of impact velocity.

c. The flying spear with the impact velocity of $40 \mathrm{~m} / \mathrm{s} \sim 50 \mathrm{~m} / \mathrm{s}$ can penetrate the aluminum honeycomb sandwich plate and embed in it, and the barbs open.

\section{References}

1. A Ashab, R Dong, G Lu, et al. Quasi-static and dynamic experiments of aluminum honeycombs under combined compression-shear loading[J]. Material and Design, 2016(97):183-194.

2. N Michihata, H Matsui, K Fushimi. An inverse parallel genetic algorithm for the identification of skin/core debonding in honeycomb aluminium
panels[J]. Structural Control \& Health Monitoring, 2015, 22(12):1426-1439.

3. V Crupi, G EpastoE, Guglielmino. Comparison of aluminium sandwiches for lightweight ship structures: honeycomb vs. foam $[\mathrm{J}]$. Marine Structures, 2013, 30: 74-96.

4. P Ren, W Zhang, JH Liu et al. Dynamic analysis of aluminium alloy honeycomb core sandwich panels subjected to underwater shock loading[J]. Journal of Vibration \& Shock, 2016, 35(2): 7-11.

5. Y Song, Z Wang, T Zhao, et al. Dynamic response of foam sandwich plates subjected to impact loading $[\mathrm{J}]$. Explosion \& Shock Waves, 2010, 30(3):301-307.

6. J Huang, Z Ma, S Lan, et al. Study on Hypervelocity Impact Characteristics for Honeycomb Sandwich with Multi-Layer Insulation[J]. Journal of Astronautics, 2010,31(8):2043-2049.

7. M Hozhar, K Sotoush, M Habinollah , et al. Finite element analysis of foam-filled honeycomb structures under impact loading and crash-worthiness design[J]. Taylor \& Francis, 2015, 21(2): 2043-2049.

8. S Li, X Li, Z Wang, et al. Finite element analysis of sandwich panels with stepwise graded aluminum honeycomb cores under blast loading $[\mathrm{J}]$. Composites Part A, 2016, 80:1-12.

9. H Zhou, X Wang, Z Zhao. High velocity impact mitigation with gradient cellular solids[J]. Composites Part B: Engineering, 2016, 85: 93-101.

10. M Shan, J Guo, E Gill. Review and comparison of active space debris capturing and removal methods[J]. Progress in Aerospace Sciences, 2015, 80:18-32.

11. M M Castronuovo. Active space debris removal-A preliminary mission analysis and design[J]. Acta Astronautica, 2011, 69(9-10):848-859.

12. S I Nishida, S Kawamoto, Y Okawa, et al. Space debris removal system using a small satellite[J]. Acta Astronautica, 2009, 65(1):95-102.

13. J Jianping. Determination of the ThermoViscoplastic Constitutive Relations of 45 \# Steel[J]. Transactions of Beijing Institute of Technology, 2008.

14. W Zhang, G Wei, X Xiao. Constitutive relation and fracture criterion of $2 \mathrm{~A} 12$ aluminum alloy[J]. Binggong Xuebao/acta Armamentarii, 2013, 34(3):276-282. 